\title{
Design of a Bimorph Piezoelectric Energy Harvester for Railway Monitoring
}

\author{
Jingcheng Li*, Shinae Jang* ${ }^{\dagger}$ and Jiong Tang**
}

\begin{abstract}
Wireless sensor network is one of prospective methods for railway monitoring due to the long-term operation and low-maintenance performances. How to supply power to the wireless sensor nodes has drawn much attention recently. In railway monitoring, the idea of converting ambient vibration energy from vibration of railway track induced by passing trains to electric energy has made it a potential way for powering the wireless sensor nodes. In this paper, a bimorph cantilever piezoelectric energy harvester was designed based on a single degree-of-freedom model. Experimental test was also performed to validate the design. The first natural frequency of the bimorph piezoelectric energy harvester was decreased from $117.1 \mathrm{~Hz}$ to $65.2 \mathrm{~Hz}$ by adding 4 gram tip mass to the free end of the 8.6 gram energy harvester. In addition, the power generation of the piezoelectric energy harvester with 4 gram tip mass at resonant frequency was increased from $0.14 \mathrm{~mW}$ to $0.74 \mathrm{~mW}$ from $2.06 \mathrm{~m} / \mathrm{s}^{2}$ base excitation compared to stand-alone piezoelectric energy harvester without tip mass.
\end{abstract}

Keywords: Piezoelectric, Energy Harvesting, Railway, Structural Health Monitoring

\section{Introduction}

Wireless smart sensors have drawn significant attention in general structural health monitoring realm in recent years due to its wireless, low cost, and versatility. Especially, wireless sensor network with self-powered ability have been of increasingly interests for the rails with high demand in railway monitoring under natural and manmade disasters. In general, energy generated from ambient environment such as solar power, wind energy, vibration energy, etc., can be stored in energy storage devices to provide power for the wireless sensors. By powering these wireless sensors from ambient energy, the performance of the sensor networks will be improved and the maintenance costs will be reduced [1]. In railway monitoring, the vibration energy from railway track induced by passing train is a large amount energy which can be used for powering wireless sensors.
Electromagnetic, electrostatic and piezoelectric are the most commonly used energy harvesting mechanisms for converting vibration energy to electric energy [2]. The comparison of these three mechanisms for microsystem has been summarized by Beeby et al. [3]. While each type of these three mechanisms has its benefits for certain applications, it appears that piezoelectric energy harvesters are capable for generating electric power from vibration energy for wireless sensor nodes since recent studies show wireless sensors used for railway monitoring requiring as low as a few $\mathrm{mW}$ [4].

As the development of piezoelectric energy harvesting, a cantilever beam with piezoelectric material attached to the top and bottom surfaces becomes an attractive structure for harvesting energy from ambient excitation. Glynne-Jones et al. [5] investigated the power output of a generator fabricated by piezoelectric materials attached to the top and bottom of a $0.1 \mathrm{~mm}$

[Received: November 1, 2012, Revised: November 23, 2012, Accepted: November 26, 2012] *Civil and Environmental Engineering Department, University of Connecticut, Storrs, CT 06269, U.S., **Mechanical Engineering Department, University of Connecticut, Storrs, CT 06269, U.S. †Corresponding Author, Email: sjang@engr.uconn.edu

(c) 2012, Korean Society for Nondestructive Testing 
stainless steel beam, a maximum power of $3.3 \mu \mathrm{W}$ was generated under a frequency of $80.1 \mathrm{~Hz}$ with optimal resistive load of $333 \mathrm{k} \Omega$. Similar study has been performed in the work of duToit et al. [6] for validating the mathematical model. However, a maximum power of $586 \mu \mathrm{W}$ was measured with $2.5 \mathrm{~m} / \mathrm{s}^{2}$ base acceleration at resonant frequency. Similar results can also be found in Erturk and Inman's work [7]. In addition, a bimorph piezoelectric cantilever beam generator with proof mass on the free end was developed by Roundy et al. [8, 9]. Proof mass on the free end significantly increase the power output of the piezoelectric cantilever beam. A maximum power output of nearly $80 \mu \mathrm{W}$ with a power density of $70 \mu \mathrm{W} / \mathrm{cm}^{3}$ was produced with a $250 \mathrm{k} \Omega$ load resistor, at $2.5 \mathrm{~m} / \mathrm{s}^{2}$ input acceleration and resonant frequency of $120 \mathrm{~Hz}$. After optimal design, the power density could be improved to be $250 \mu \mathrm{W} / \mathrm{cm}^{3}$ from a vibration source of $2.5 \mathrm{~m} / \mathrm{s}^{2}$ at $120 \mathrm{~Hz}$. On the other hand, in railway monitoring, the first resonant frequency of a cantilever beam structure can be easily tuned to be close to the excitation frequency from the passing train, which means that the cantilever beam structure can be excited around resonant frequency at most of time to get the maximum power output. In addition, the first resonant frequency of the cantilever beam structure can be further reduced by the addition of a tip mass. Those reasons above make the cantilever piezoelectric energy harvester one of potential solutions to long-term, low maintenance power supply for distributed wireless sensor nodes.

In order to design an efficient cantilever piezoelectric energy harvester from the excitation of railway track induced by passing train, the characteristics of the railway track vibration should be considered regarding to the dominant vibration frequency. The main mechanisms of railway vibration arise from dynamic forces at wheel/rail, and rail/ground interfaces. The wheel/ rail interface refers to rail vibration under moving wheel, and wheel/rail unevenness, while the rail/ground interface refers to the groundborne vibration [10,11]. Many factors influence the vibration of railway track including train speed, length of rail car, rail and wheel roughness and material properties of the foundation et al.. An experimental test was carried out by Chatterjee et al. [12] for determining the track responses during the passage of trains at variable speeds. A dominant rail vibration frequency less than $5 \mathrm{~Hz}$ can be found in each train speed which was contributed by the passage of all axles and bogies. On the other hand, a dominant rail vibration frequency range between $20 \mathrm{~Hz}$ and $80 \mathrm{~Hz}$ can also be found which was caused by the wheel and rail roughness at variable train speeds. Similar results were also presented by Degrande et al. [13]. To date, most energy harvesters employed to harvest energy from vibrations or vibration structures are operated in resonance at single excitation frequency. However, in railway monitoring, the dominant rail excitation frequency is a range rather than a single excitation frequency which requires the energy harvester can be worked in a broad frequency range. In order to design such an energy harvester, the first step will be designing an energy harvester whose resonant frequency will be within the rail excitation frequency range, and the second step is to broaden the working frequency.

In this paper, a cantilever bimorph piezoelectric energy harvester with tip mass whose resonant frequency is between $20 \mathrm{~Hz}$ and $80 \mathrm{~Hz}$ is designed based on a single degreeof-freedom model for simplicity. The feasibility of the single degree-of-freedom model is validated from experimental tests. In addition, the effect of the tip mass of the piezoelectric energy harvester is investigated on natural frequency modification to maximize power 
generation. Based on the theoretical and experimental results, further work in widening the working frequency of the harvester will be performed in future.

\section{Mathematical Model}

A simple single degree-of-freedom (lumped parameter) model is used in this paper for simplicity (The limitations of the single degreeof-freedom model have been discussed by Erturk and Inman [14]). Fig. 1 shows the schematic of such a system where $m$ is the system mass, $k$ is the spring of stiffness, and $c_{T}$ is the total damping coefficient. The system is being excited by an external sinusoidal vibration $y(t)=Y \sin (\omega$ t) (where $Y$ is the amplitude of the acceleration and $\omega$ is the vibration frequency), resulting in the mass moves as $z(t)$. The equation of motion of the system is described in Eq. (1).

$$
m \ddot{z}(t)+c_{T} \dot{z}(t)+k z(t)=-m \ddot{y}(t)
$$

Since energy is extracted from relative movement between the mass and the base, the maximum power is generated when the excitation frequency matches the natural frequency of the system $\omega_{n}=\sqrt{k / m}$. And total damping ratio $\left(\zeta_{t}=k / 2 m \omega_{n}\right)$ prevents the power goes to infinity when the generator vibrates at resonant frequency.

Fig. 2 shows the schematic of a bimorph piezoelectric energy harvester with and without tip mass in series connection. It can convert the vibration energy to electric energy.

Based on Challa's work [15], the open voltage $V_{0}$ generated from the system depends on the stress $\sigma$ developed in the structure and the material properties of the piezoelectric patch, as shown in Eq. (2):

$$
V_{0}=\frac{-d_{31} t_{p} \sigma_{n}}{\varepsilon}
$$

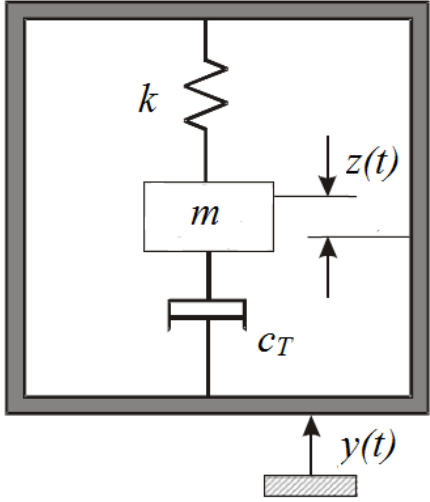

Fig. 1 Single degree-of-freedom model

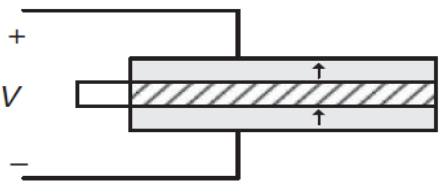

(a) Piezoelectric without tip mass

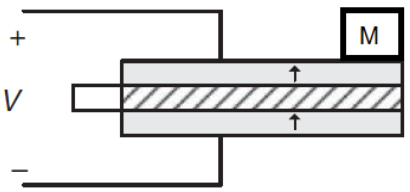

(b) Piezoelectric with tip mass

Fig. 2 Schematic of a bimorph piezoelectric energy harvester with and without tip mass in series connection

where $t_{p}$ is the thickness of the piezoelectric layer, $-d_{31}$ is the piezoelectric strain constant, and $\varepsilon$ is the dielectric constant of the piezoelectric material, and $\sigma_{n}$ is the piezoelectric stress at resonant frequency:

$$
\sigma_{n}=\frac{3 E Y h}{4 L^{2} \zeta_{t} \omega_{n}^{2}}
$$

where $E$ is the effective modulus of the beam, $h$ is the distance of the piezoelectric layer from the neutral axis, $L$ is the length of the beam. $\omega_{n}=\sqrt{k_{e f f} / m_{e f f}}, k_{e f f}=3 E I / L^{3}, m_{e f f}=33 m_{b} / 140+m_{t}$, $m_{b}$ is the total mass of the beam, and $\mathrm{mt}$ is the tip mass. The damping ratio can be obtained by 
performing a flick test, through which an amplitude decay plot is obtained and the corresponding damping is determined by:

$$
\zeta=\frac{1}{2 \pi} \operatorname{In} \frac{a_{1}}{a_{2}}
$$

The power generated from the piezoelectric energy harvester can be calculated such that:

$$
P_{p}=\frac{V_{0}^{2} R_{L p}}{\left(R_{s}+R_{L p}\right)^{2}}
$$

where $R_{\mathrm{S}}$ is the internal resistance and $R_{L p}$ is the applied load resistance. As can be seen from Eq. (5), the maximum power can be reached when the applied load resistance equals to the internal resistance. Therefore, a theoretical model to design an energy harvester for wireless sensors has been derived.

\section{Experimental Setup}

To design an appropriate energy harvester prototype for railway monitoring, an experimental set up has been prepared with piezoelectric material and tip masses. The bimorph piezoelectric harvester used in this study was from Piezo System, Inc.(T226-A4-503X) [16], which consisted of two equal size PZT-5A piezoelectric elements bracketing a brass substructure layer, and the piezoelectric elements were connected in series. The material used in this paper is similar to those used by duToit et al. [6] and Erturk and Inman [7]. The geometry and material properties of the piezoelectric energy harvester are presented in Table 1.

Three piezoelectric energy harvesters have been designed based on the theoretical model described in Section 2: design 0, 1, and 2 (see Fig. 3). Design 0 has no tip mass at the free end, while Design 1 has one tip mass, and Design 2 has two. The tip mass was made of aluminum with 2 gram for each. Based on the mathematical model, the first natural frequency of the design 0 was $120.3 \mathrm{~Hz}$ which was out of the dominant rail vibration frequency range. Two prototypes of piezoelectric energy harvesters with

Table 1 Geometry and material properties of the piezoelectric energy harvester

\begin{tabular}{lcc|lcc}
\hline \multicolumn{1}{c|}{ Property } & Symbol & Values & \multicolumn{1}{c}{ Property } & Symbol & Values \\
\hline \hline Length $(\mathrm{mm})$ & $L$ & 50.8 & Brass modulus $(\mathrm{GPa})$ & $E_{s}$ & 105 \\
Width $(\mathrm{mm})$ & $b$ & 31.8 & Piezo modulus $(\mathrm{GPa})$ & $E_{p}$ & 66 \\
Brass thickness $(\mathrm{mm})$ & $t_{s}$ & 0.14 & Tip mass $(\mathrm{kg})$ & $M_{t}$ & $0.002(\mathrm{each})$ \\
Piezo thickness $(\mathrm{mm})$ & $t_{p}$ & $0.26(\mathrm{each})$ & Piezo dielectric constant $(\mathrm{F} / \mathrm{m})$ & $\bar{\varepsilon}_{33}^{S}$ & $1500 \varepsilon_{0}$ \\
Brass density $\left(\mathrm{kg} / \mathrm{m}^{3}\right)$ & $\rho s$ & 9000 & Piezo strain constant $(\mathrm{pm} / \mathrm{V})$ & $d_{31}$ & -190 \\
Piezo density $\left(\mathrm{kg} / \mathrm{m}^{3}\right)$ & $\rho_{p}$ & 7800 & & & \\
\hline
\end{tabular}

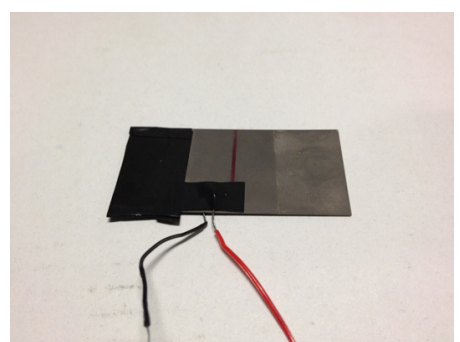

(a) Design 0

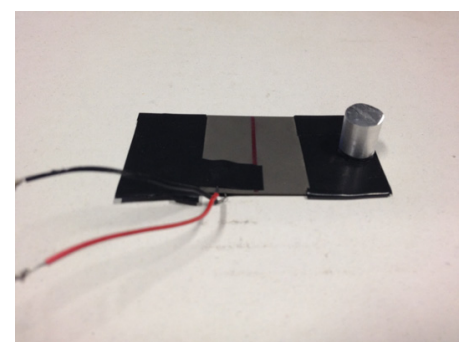

(b) Design 1

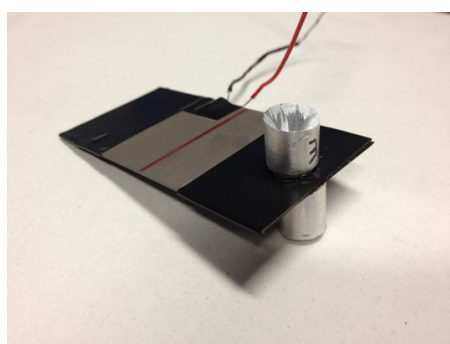

(c) Design 2

Fig. 3 Piezoelectric energy harvester prototype a) design 0 without tip mass b) design 1 with one tip mass c) design 2 with two tip mass 

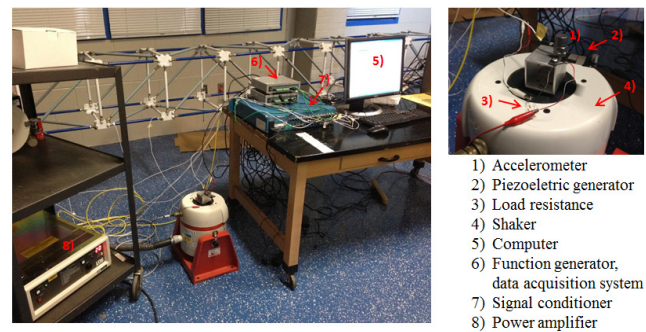

Fig. 4 Experimental setup for the validation of the mathematical model

tip mass were designed. The natural frequency of design 1 and design 2 was $85.3 \mathrm{~Hz}$ and $69.7 \mathrm{~Hz}$, respectively, where only design 2 was within the railway dominant vibration frequency.

The experimental setup is shown in Fig. 4. One end of the bimorph piezoelectric energy harvester was free, while the other end was clamped and excited from the base by a shaker connected to a function generator via a power amplifier. The generated voltage from the energy harvester was measured by connecting it to a data acquisition system. In addition, an accelerometer was attached on the clamped end of the piezoelectric energy harvester to measure the base acceleration. The load resistors were shunted between the piezoelectric elements. Experimental tests will be performed to validate the feasibility of the mathematical model. The natural frequencies and energy outputs of the three piezoelectric harvesters will be compared between the mathematical and experimental results.

\section{Results and Discussions}

Using the experimental setup described in section 3, several results have been found. Firstly, as shown in Fig. 5, the first natural frequencies of the three piezoelectric bimorph energy harvesters, Design 0,1 and 2, were $117.1 \mathrm{~Hz}, 80.3 \mathrm{~Hz}$, and $65.2 \mathrm{~Hz}$, respectively, while those were predicted by the mathematical model to be $120.3 \mathrm{~Hz}, 85.3 \mathrm{~Hz}$ and $69.7 \mathrm{~Hz}$, respectively. Given those material properties by

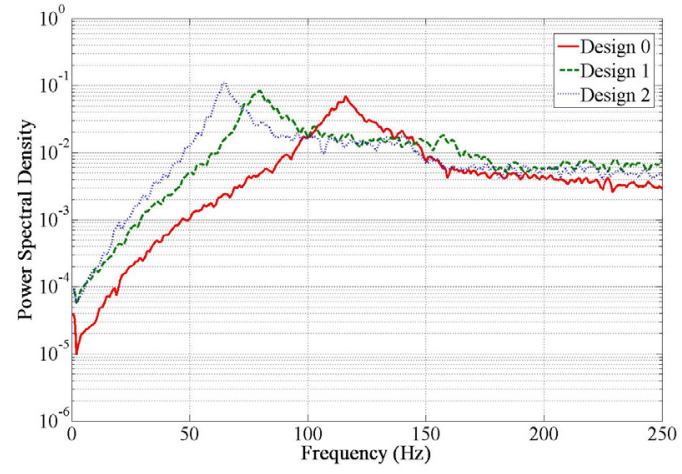

Fig. 5 Power spectral density of the piezoelectric energy harvester

the producer, the results for the first natural frequency agreed very well. In addition, as the weight of tip mass increased, the first natural frequency of the energy harvester decreased. By adding 4 gram tip mass to the free end of the piezoelectric energy harvester, the natural frequency decreased from $117.1 \mathrm{~Hz}$ to $65.2 \mathrm{~Hz}$ from the experimental data. Because the excitation frequency of railway track by passing train is low, the first natural frequency could be further reduced by heavier tip mass. Nonetheless, at this stage, design 2 matches the objective of this study which designing an energy harvester whose resonant frequency is within the dominant rail vibration frequency range.

Secondly, the effect of tip mass in increasing the maximum energy output with the optimal load resistance at resonant frequency was investigated. Thirteen different resistances 1 , $3.3,4.8,6.7,9.9,11.8,14.9,19.4,26.5,50.5$, $67.9,98.6$, and $118 \mathrm{k} \Omega$ were used. The base excitation was measured to be $0.21 \mathrm{~g}\left(2.06 \mathrm{~m} / \mathrm{s}^{2}\right)$ and was held constant during these tests by monitoring the base acceleration. The damping ratio of the prototypes was measured to be 0.018 . The power and voltage responses of the three piezoelectric energy harvesters at different load resistances are shown in Fig. 6 and 7, respectively. From Fig. 6, generally, the power increases as the resistance increases before it 


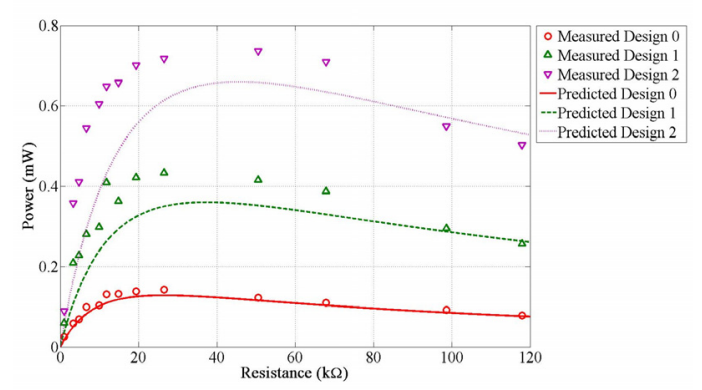

Fig. 6 Comparison of predicted and measured power output versus resistance under $0.21 \mathrm{~g}$ base excitation at resonant frequency

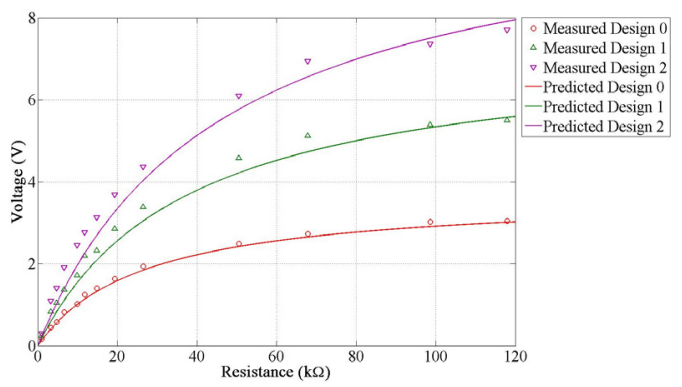

Fig. 7 Comparison of predicted and measured voltage output versus resistance under $0.21 \mathrm{~g}$ base excitation at resonant frequency

reaches the optimal resistance, then the power decreases when the resistance keeps on increasing. The maximum power generated by design 0 , design 1 and design 2 were measured to be $0.14,0.43$ and $0.74 \mathrm{~mW}$, while the predicted results were $0.13,0.36$, and $0.66 \mathrm{~mW}$, respectively, resulting in $7.14 \%, 16.30 \%$ and $10.81 \%$ error. In addition, by adding tip mass to the free end, the maximum power generated by design 1 and design 2 increased $176.9 \%$ and $407.7 \%$ from measured data compared to design 0 . Moreover, the mathematical model underestimated the power generated from the energy harvesters. The optimal resistances predicted by the model were 26.5, 37.3 and $45.6 \mathrm{k} \Omega$ for design 0 , design 1 and design 2 , respectively. While from the plot, the optimal resistance for design 0 is between 20 and $26.5 \mathrm{k} \Omega$, and between $26.5 \mathrm{k} \Omega$ and $50.5 \mathrm{k} \Omega$ for design 1 and design 2 from measured data. Furthermore, the optimal load resistance increases as the tip mass increases from the plot.

In addition, the voltage output versus resistances under the first natural frequency at $0.21 \mathrm{~g}$ base acceleration for the three harvesters is shown in Fig. 7. From the plot, the voltage of the three generators increase rapidly at beginning, and then increase slowly after the optimal load resistance for both predicted and experimental data. The voltage reaches the maximum at the maximum resistance. Similar to power output, the mathematical model underestimated the voltage output from the energy harvesters. In general, reasonable agreements have been found between the predicted and measured electrical responses from Fig. 6 and 7 .

\section{Conclusions}

A bimorph piezoelectric energy harvester with tip mass whose resonant frequency is within the dominant rail vibration frequency range was designed. With the tip mass in energy harvester, the natural frequency was decreased and the maximum energy output was increased at the resonant frequency. In addition, a SDOF model was validated to predict the natural frequency and power output of the piezoelectric energy harvester. From the test results, the first natural frequency of the generators decreased from $117.1 \mathrm{~Hz}$ to $80.3 \mathrm{~Hz}$ and $65.2 \mathrm{~Hz}$ by adding 2 gram and 4 gram tip mass to the free end of the cantilever bimorph piezoelectric energy harvester, respectively. Meanwhile, by adding the 2 gram and 4 gram tip mass, the maximum energy output at resonant frequency with optimal resistance under base excitation of $0.21 \mathrm{~g}$ increased from $0.14 \mathrm{~mW}$ to $0.43 \mathrm{~mW}$ and $0.74 \mathrm{~mW}$, respectively. Generally, good agreements have been found between the experimental and mathematical data. Further study on designing an efficient 
energy harvester for wireless sensor nodes used in railway monitoring is underway including field tests to obtain the ambient frequency, track deflection and strain information of the railway track by passing train; to broaden the working frequency of the energy harvester based on the dominant rail vibration frequency range; and to validate the feasibility of the design by field tests .

\section{Acknowledgement}

This material is based upon work supported by the U.S. Department of Homeland Security under Grant Award Number 2008-ST-061TS002. The generous supports are gratefully acknowledged. The views and conclusions contained in this document are those of the authors and should not be interpreted as necessarily representing the official policies, either expressed or implied, of the U.S. Department of Homeland Security.

\section{References}

[1] G. Park, T. Rosing, M. D. Todd, C. R. Farrar and W. Hodgkiss, "Energy harvesting for structural health monitoring sensor networks," Journal of Infrastructure Systems, ASCE, Vol. 14, No. 1, pp. 64-79 (2008)

[2] C. B. Williams and R. B. Yates, "Analysis of a micro-electric generator for microsystems," Sensors and Actuators, Vol. 52, pp. 8-11 (1996)

[3] S. P. Beeby, M. J. Tudor and N. M. White, "Energy harvesting vibration sources for microsystems applications," Measurement Science and Technology, Vol. 17, pp. 175-195 (2006)

[4] S. Jang, H. Jo, S. Cho, K. Mechitov and J. Rice, "Structure health monitoring of a cable-stayed bridge using smart sensor technology: deployment and evaluation," Smart Structures and Systems, Vol. 6, No. 5-6, pp. 439-459 (2010)

[5] P. Glynne-Jones, S. P. Beeby and N. M. White, "Towards a piezoelectric vibration powered microgenerator," IEEE Science Measurement and Technology, Vol. 148, No. 2, pp. 68-72 (2001)

[6] N. E. duToit and B. L. Wardle, "Experimental verification of models for microfabricated piezoelectric vibration energy harvesters," AIAA Journal, Vol. 45, pp. 1126-1137 (2007)

[7] A. Erturk and D. J. Inman, "An experimentally validated bimorph cantilever model for piezoelectric energy harvesting from base excitations," Smart Materials and Structures, Vol. 18, 025009 (2009)

[8] S. Roundy, P. K. Wright and J. Rabaey, "A study of low lever vibration as a power source for wireless sensor nodes," Computer Communication, Vol. 26, pp. 1131-1144 (2003)

[9] S. Roundy and P. K. Wright, "A piezoelectric vibration base generator for wireless electronics," Smart Materials and Structures, Vol. 13, pp. 1131-1142 (2004)

[10] S. A. Suhairy, "Prediction of Ground Vibration from Railways," SP Swedish National Testing and Research Institute, SP Report (2000)

[11] Aylesbury Vale Parkway Development Railway Vibration. MM Doc Ref: 229338/46 Rev. A (2007)

[12] P. Chatterjee, G. Degrande, S. Jacobs, J. Charlier, P. Bouvet and D. Brassenx, "Experimental results of free field and structural vibrations due to underground railway traffic," $10^{\text {th }}$ International Congress on Sound and Vibration, Stockholm, Sweden (2003)

[13] G. Gegrande, P. Chatterjee, W. Van de Velde, P. Hölscher, V. Hopman, A. Wang, 
N. Dadkah and R. Klein, "Vibration due to a test train at variable speeds in a deep bored tunnel embedded in London clay," $11^{\text {th }}$ International Congress on Sound and Vibration, St-Petersburg, Russis (2004)

[14] A. Erturk and D. J. Inman, "Issues in mathematical modeling of piezoelectric energy harvester," Smart Material and Structure, Vol. 17, 065016 (2009)
[15] V. R. Challa, M. G. Prasad and F. T. Fisher, "A coupled piezoelectric-electromagnetic energy harvesting technique for achieving increased power output through damping matching," Smart materials and Structures, Vol. 18, 095029 (2009)

[16] Piezo Systems, Inc. http://www.piezo.com/ prodbm1brass.html 